\title{
Chitosan Plasma Chemical Processing in Beam-Plasma Reactors as a Way of Environmentally Friendly Phytostimulants Production
}

\author{
Tatiana Vasilieva ${ }^{1, *}$, Oscar Goñi ${ }^{2}$, Patrick Quille ${ }^{2}$, Shane $\mathrm{O}^{\prime}$ Connell $^{2}$, Dmitry Kosyakov ${ }^{3}{ }^{\circledR}$, Semen Shestakov ${ }^{3}$, \\ Nikolay Ul'yanovskii ${ }^{3}$ and Michael Vasiliev ${ }^{4}$ \\ 1 Department of General Chemistry, Moscow Institute of Physics and Technology, Dolgoprudny, \\ 141700 Moscow, Russia \\ 2 Plant Biostimulant Group, Shannon Applied Biotechnology Centre, Institute of Technology Tralee, Tralee, \\ Co. Kerry V92 CX88, Ireland; Oscar.Goni@staff.ittralee.ie (O.G.); Patrick.quille@staff.ittralee.ie (P.Q.); \\ shane.oconnell@staff.ittralee.ie (S.O.) \\ 3 Core Facility Center "Arktika", Northern (Arctic) Federal University, Severnaya Dvina Emb., 17, \\ 163002 Arkhangelsk, Russia; kosyakov@mail.ru (D.K.); s.shestakov@narfu.ru (S.S.); \\ uluanovskii@mail.ru (N.U.) \\ 4 Aerospace Research Department, Moscow Institute of Physics and Technology, Dolgoprudny, \\ 141700 Moscow, Russia; vasilev.mn@mipt.ru \\ * Correspondence: tmvasilieva@gmail.com; Tel.: +7-916-550-2740
}

check for updates

Citation: Vasilieva, T.; Goñi, O.; Quille, P.; O'Connell, S.; Kosyakov, D.; Shestakov, S.; Ul'yanovskii, N.; Vasiliev, M. Chitosan Plasma Chemical Processing in Beam-Plasma Reactors as a Way of Environmentally Friendly Phytostimulants Production. Processes 2021, 9, 103. https:// doi.org/10.3390/pr9010103

Received: 27 October 2020 Accepted: 4 January 2021 Published: 6 January 2021

Publisher's Note: MDPI stays neutral with regard to jurisdictional clai$\mathrm{ms}$ in published maps and institutional affiliations.

Copyright: (C) 2021 by the authors. Licensee MDPI, Basel, Switzerland. This article is an open access article distributed under the terms and conditions of the Creative Commons Attribution (CC BY) license (https:// creativecommons.org/licenses/by/ $4.0 /)$.

\begin{abstract}
A novel technique of phytoactive water-soluble chitooligosaccharide (COS) production in low-temperature plasma is described. Design, operation, and control of plasma chemical reactors used to produce COS from the powder of high molecular weight chitosan are presented. The electron beam plasma is strongly non-equilibrium and chemically active; plasma was excited by injecting the scanning electron beam into reaction volume filled with aerosol, containing oxygen and chitosan powder. Plasma chemical processes, responsible for the raw chitosan destruction and techniques of these processes to obtain control of products of optimal molecular weight, are considered. COS, in amounts sufficient for laboratory tests with some plants, were produced. Tests showed that the addition of COS into the liquid growing medium at 0.25 and $1 \mathrm{mg} / \mathrm{mL}$ stimulates root growth in Arabidopsis thaliana seedlings (Col-0) by up to $40 \%$, with respect to control plants. Foliar application of these COS formulations at $0.25 \mathrm{mg} / \mathrm{mL}$ on tomato plants (cv. Micro-Tom) also resulted in increases between $11.9 \%$ and $36 \%$ in two important plant productivity indicators (flower and fruit numbers) compared to the control plants. Being environmentally friendly (and resource saving) the electron beam plasma technology of renewable natural biopolymer processing can be considered as a competitive way to produce biostimulants for commercial agriculture.
\end{abstract}

Keywords: plasma chemical processing; electron-beam plasma; chitooligosaccharides; plant biostimulants

\section{Introduction}

A natural renewable and technologically safe biopolymer chitosan and its depolymerized products, chitooligosaccharides (COS), are of interest for a number of commercial applications in the biomedical, food, and chemical industries, as well as in environmental protection and wastewater management $[1,2]$. This is owing to their antimicrobial, antioxidant, hypocholesterolemia activities, immunity-enhancing and antitumor effects, as well as ion absorption acceleration ability [2,3].

Recently, the agricultural applications of chitosan and COS have been actively studied, due to their effects on plant defense-related cellular responses to stresses [1-4]. Moreover, chitosan-based materials have been used to produce nanoparticles able to efficiently supply plants with chemicals and nutrients [5]. On the other hand, a broad range of chitosan and COS formulations have shown benefits for plant growth and development parameters [2,4]. They have been used to augment foliar biomass [6], influence shoot, and root growth, both in vitro and in vivo experiments [7], increase flower numbers [8], enhance 
crop yield [2,9], spike number and grains per spike [10], improve seed germination [11], or alleviate iron deficiency chlorosis symptoms [12] in various crop, cereal, ornamental, fruit, and medicinal plants.

The most important limitation for chitosan agricultural applications relates to its insolubility at neutral $\mathrm{pH}$ and high viscosity [1,13]. To produce water-soluble chitosan solutions, different depolymerization techniques have been suggested to generate COS, including chemical hydrolysis, enzymatic degradation, treatment by $\mathrm{H}_{2} \mathrm{O}_{2}$ or $\mathrm{NaNO}_{2}[1,13]$, and physical methods (such as hydrothermal, microwave, ultra-sonication, $\gamma$-irradiation, and high-energy ion and electron beams) $[14,15]$. Although the low-cost chemical hydrolysis in concentrated acids or alkalis at high temperature is a conventional and simple method used in industry, the complexity to control the reaction progress may cause the formation of secondary compounds or accumulation of monomers [14]. Toxic wastes, such as hazardous alkaline, acid solutions, and environment contamination are also inherent in the chemical processing of chitin and chitosan [16-19]. Enzymatic hydrolysis of chitin and chitosan has been proposed as an alternative method because the reaction is performed under milder conditions and the molecular mass distribution of the product is more controllable [20]. However, the enzymes have very different binding affinities for different sequences on the substrate, reactions have multiphasic kinetics, and the product mixtures obtained at the end of each of these phases differ considerably. The high cost of chitinases and chitosanases limits their wide application on an industrial scale [16]. Both chemical and enzymatic methods of chitin and chitosan degradation are time-consuming multi-stage procedures and usually take several hours [14,20]. Both advantages and power efficiency of the chitosan processing in Electron-Beam Plasma (EBP), as well as the cost of the used Electron-Beam Plasma Chemical Reactor, are discussed in Section 3.4.

Electrophysical processes are the basis of numerous technologies of polymer materials modification. In particular, the power of microwave (MW) electromagnetic field is known to be able to modify physical and chemical properties of these materials due to thermal and non-thermal action. Intensive polymer heating can cause thermal chitosan destruction up to its pyrolysis. Non-thermal processes could be more interesting because they have a softer effect on the material. Unfortunately, chitosan does not contain groups that form strong dipoles (e.g., epoxy, hydroxyl, amino, cyanate, etc.) and, therefore, practically unsuitable for direct non-thermal MW processing [13-16].

Microwave excitation readily forms plasmas at reduced gas pressures and, under some circumstances, at pressures in excess of $1 \mathrm{~atm}$. MW-plasmas interact with surfaces in one of two ways beyond simply providing thermal energy for heating. Atomic or ionic species in the plasma may react with the substrate to form volatile constituents (etching), or species in the plasma may react to form materials deposited on the substrate. Obviously, both of these processes are inapplicable to produce low-molecular weight water-soluble COS.

Mechanochemical chitosan powder processing, e.g., ultrasonic treatment, seems to be applicable to settle this engineering problem, but requires an elastic medium surrounding powder particles, which could deliver acoustic energy to them. This is the reason why these processes can be realized in suspensions and solutions only [13-16].

Thus, partial chitosan depolymerization in known physical processes has some limitations, such as difficulties in treatment conditions control, high power consumption, and equipment operation complexity [14]. However, plasma chemical technologies based on non-equilibrium low temperature plasmas could be considered as a promising alternative to chemical and biochemical techniques as well as to physical methods mentioned above.

Products of plasma chemical processing of objects and materials of agricultural and biotechnologies can find numerous applications. For example, the seed treatment with non-thermal atmospheric-pressure plasma or low-pressure plasma-activated water is recognized as a suitable technology to improve germination and further plant growth [21-25]. Several applications of low-temperature plasmas for the degradation of pesticides and aflatoxin $B_{1}$ [26], functionalization of extracellular heteropolysaccharides [27], improve- 
ment of zein film-forming properties [28], and flavonoids processing associated with the enhancement of biological activities have also been described [29].

The plasmachemical processes in non-equilibrium low temperature plasmas are able to substitute mentioned hydrolysis techniques of chitosan modification and derivatization. Gas discharge plasmas and chitosan destruction by a high frequency bipolar pulsed DC (direct current) discharge in liquid-phase plasma systems have been demonstrated in several studies [29-36]. However, the substrates to be processed were thin chitosan films or chitosan solutions, i.e., preliminary preparations of raw chitosan were needed. A lot of factors can affect the material treatment uniformity in discharge systems (such as possible instabilities of plasma reaction volume, complicated control of temperature distribution over the sample surfaces, including possible overheating of some reaction zones due to discharge plasma contraction and filamentation) and, therefore, the repeatability of the processing results. For these reasons, the non-equilibrium plasmas of other types may be better for large-scale technologies.

In our previous papers, the EBP excited by electron beams (EB) was suggested for the effective and controllable chitosan depolymerization to produce water-soluble COS with high yields of target products $[37,38]$. It is very important that chitosan plasma chemical processing in beam-plasma reactors is the dry process; that is, the main advantage of the reactors of the type. The target product is retrieved from the reaction chamber ready to use and no additional procedures are required. Beam-plasma reactors do not produce any toxic or hazardous gaseous and liquid exhausts, i.e., they are environmentally friendly.

The objectives of the present research were as follows:

- To upgrade the experimental setup available and adapt its operations to obtain low molecular weight chitosan oligomers in amounts sufficient for practical agricultural uses, i.e., to develop the industrial Electron-Beam Plasma Chemical Reactor (EBPR) prototype;

- To characterize properties of COS obtained by chitosan degradation under beamplasma action in the EBPR;

- To study the COS ability to stimulate important plant productivity parameters (root length, number of flowers, and fruits).

The present study results provide evidence that plasma chemical technology based on beam-plasma systems is promising for effective, resource saving, and environmentally friendly production of bioactive COS for agricultural applications.

\section{Materials and Methods}

\subsection{The Electron-Beam Plasma Chemical Reactor for Chitosan Processing and Treatment Procedure}

Under typical conditions of the EBP generation (medium pressure $0.1<P_{m}<10 \mathrm{kPa}$ and moderate EB power $N_{b}<1 \mathrm{~kW}$ ), the plasma was strongly non-equilibrium and cold. The EBP was produced in the EBPR key subsystems of which are presented in Figure 1.

The electron-beam gun (1) was located in high-vacuum chamber; (2) was connected with the power supply SR6/60 (Spellman, GA, USA) of a maximum power of $6 \mathrm{~kW}$ that generated a stabilized high-voltage of negative polarity. The gun formed thin EB (3) (continuous or interrupted) that was then transported to the working chamber (4) through injection window (IW) (5) of special design [39]. When the reaction chamber was filled with a gas, the EB generated a cloud of chemically active plasma (6) due to ionization, excitation, and dissociation of gas molecules. Cylindrical reaction chamber (7) was placed in a certain zone of the working chamber coaxially with the EB injected; the front end of the cylinder was open for the EB injection and the other one had a bottom combined with the gas feeder (8). The reaction chamber position (distance between the IW and open end of the reaction chamber) was adjusted experimentally to fully localize the plasma cloud inside it. The reaction chamber, together with the gas feeder, could rotate around the longitudinal axis in special sealed bearing (9) to continuously mix the chitosan powder preloaded in this chamber for processing. The electric drive of the reaction chamber rotation is not shown in Figure 1. 


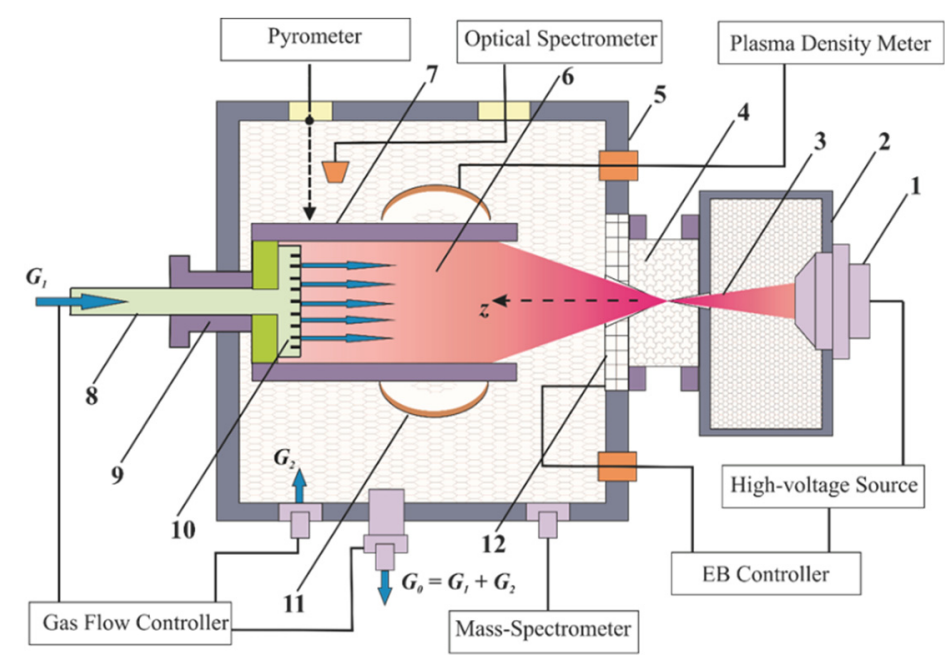

Figure 1. The scheme of the Electron-Beam Plasma Chemical Reactor: 1-electron-beam gun, 2-highvacuum chamber, 3-electron beam (EB), 4-injection window, 5-working chamber, 6-EBP-cloud, 7-cylindrical reaction chamber, 8-gas feeder, 9-sealed bearing, 10-porous insert, 11-resonator, 12 -scanning system; $G_{1}$-main gas flow, $G_{2}$-flow of gaseous additives, $G_{0}$ - gas evacuation efficiency, $z$-axis of the EB injection.

To fill the reaction chamber, the automatic system of the plasma generating gas mixture production was developed. The main gas flow $G_{1}$ was slowly blown through porous insert (10) on the reaction chamber bottom. The flow of gaseous additives $G_{2}$ could be injected into the reaction chamber directly, if required, for the plasma chemical processes control. The flows controller of the gas feeding system supported preset gas flows and sent commands to the so-called "butterfly valve" installed on the evacuation pipeline to change the gas evacuation efficiency $G_{0}=G_{1}+G_{2}$ keeping necessary gas pressure $P_{m}$. The preloaded chitosan powder dispersed over the plasma cloud by means of the gas injection and chamber rotation, as a result, creates the reaction volume in the form of the aerosol.

The multifunctional EB controller maintained the required values of the accelerating voltage $\left(E_{b}\right)$ and the EB current $\left(I_{b}\right)$ within the ranges given in Table 1 and controlled the scanning system, which supported the necessary uniformity and stability of the reaction zone at sufficiently high EB power. The scanning system (12) (Figure 1) was combined with injection window (4) and installed at the window exit. By programming the controller the EB raster of necessary shape could be formed by scanning the EB in cross-sections of the reaction chamber. Besides, the local beam power input was controlled in the longitudinal direction $z$ by varying the EB initial divergence angle. In fact, the raster pattern was a concentric ellipses system (Figure 2) and the ellipses orientation was adjusted to the reaction chamber rotation speed and direction.

Table 1. The conditions of the chitosan EBP-processing.

\begin{tabular}{cc}
\hline Parameter & Value or Characteristics \\
\hline Accelerating voltage $\left(E_{b}\right)$ & $30 \mathrm{kV}$ \\
EB current $\left(I_{b}\right)$ & $1.5-2.0 \mathrm{~mA}$ \\
Oxygen pressure $\left(P_{m}\right)$ & $0.2-1.0 \mathrm{kPa}$ \\
The EB scanning mode & Concentric ellipses \\
The reactor loading & $\approx 10 \mathrm{~g}$ per cycle \\
The distance between the injection window & $150-250 \mathrm{~mm}$ depending on gas pressure, $P_{m}$ \\
and front end of the reaction chamber & $5-10 \mathrm{~min}$ \\
Treatment time $(\tau)$ & $\approx 40{ }^{\circ} \mathrm{C}$ \\
Material temperature $\left(T_{s}\right)$ & $10^{8}-10^{10} \mathrm{~cm}^{-3}$ \\
Plasma density $\left(n_{e p}\right)$ &
\end{tabular}




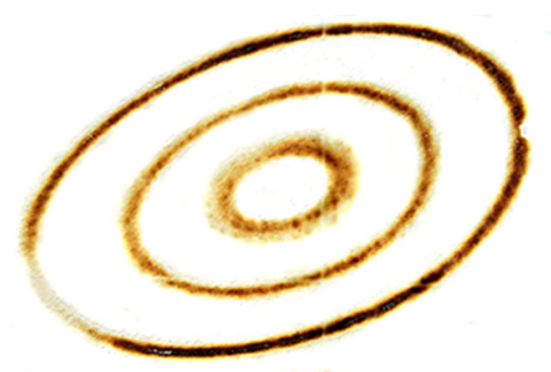

Figure 2. The raster pattern of the electron beams (EB) applied for the chitosan Electron-Beam Plasma (EBP)-processing.

Algorithms of the EB controller operation were preliminary optimized by numerical simulation of the EB propagation and absorption in aerosols. Then the simulation data were verified experimentally. Since the local beam power input cannot be measured directly the temperature, distribution along the cylindrical wall of the reaction chamber was studied. The wall temperature was measured by the optical IR-pyrometer Optris LS (Optris GmbH, Berlin, Germany). The pyrometer was preliminary calibrated by a miniature thermosensor inserted into the reaction zone simulating a single chitosan powder particle. These experiments showed that the temperature difference between the reaction chamber wall and thermo-probe did not exceed 20\%. Therefore, temperature measurements by the pyrometer were sufficiently adequate for the experiment.

The pyrometer was also used to monitor the temperature regime of the chitosan treatment process. To prevent the polysaccharides thermal destruction, they were processed at material temperature $T_{s}=40^{\circ} \mathrm{C}$. The powder temperature was controlled by varying only the EB current value whereas other reactor operation parameters (electron gun accelerating voltage, gas pressure, EB scanning mode, reaction chamber rotation frequency) were fixed. The EB current controller and pyrometer had a feedback to keep preset process temperature automatically. The ranges of optimal conditions for the chitosan EBP-processing are summarized in Table 1 . The range of plasma density $n_{e p}$ typical for chitosan processing in the EBPR under consideration are also given in Table 1. The plasma density was measured by means of the microwave technique of plasma diagnostics described in detail in [40] and specially adapted to experiments with aerosol plasmas.

Two important subsystems of the experimental setup should be mentioned specially. Since the EBP radiation supplies valuable information about plasma chemical processes, the emission spectra of the plasma were taken in various zones of the reaction volume. Spectrometers of UV, visible and IR ranges were used in preliminary experiments on aerosol plasmas studies and some results of these experiments are presented in [41]. For technological experiments with real EBPR mass-spectrometry turned out to be more useful. Mass-spectrometer HALO 201-RC (Hiden Analytical, Warrington, UK) continuously monitored plasma generating medium composition. In particular, it could detect possible gaseous pollutants emitted by chitosan under the plasma treatment [42]: the total gas flow $G_{1}+G_{2}$ must be sufficient to neglect these pollution exhausts. To prevent the plasma generating medium from pollution by residual air the working chamber was preliminary evacuated to a pressure of $\sim 1 \mathrm{~Pa}$ after every reactor reloading and only then the chamber was filled with oxygen of spectroscopic grade (Scientific Industrial Center of National Research Center "Kurchatov Institute", Moscow, Russia), which was used in the most experiments. Exact oxygen pressure values within the range 100-1000 Pa were found experimentally and downloaded in the gas flow controller for every combination of accelerating voltage, EB current, and scanning mode. Then, the controller kept preset $P_{m}$ value automatically.

The original water-insoluble crab shell chitosan powder for further EBP-treatment was obtained from Bioprogress Co., Russia, and certified by the manufacturer. In accordance with the manufacturer specifications, the original substance has viscosity-average molecular weight, $M_{v}=500 \mathrm{kDa}$, the deacetylation degree $D D=90.0 \%$ and polydispersity index 1.5 ; 
characteristic particle size was $\sim 100 \mu \mathrm{m}$. The viscosimetry is the conventional technique for determining the polymers molecular weight applied by chitosan manufactures because it is simple and quick. In addition, $M_{v}$ is directly proportional to the average molecular weight of the polymer [43] we dealt with in the present study for COS characterization. The chitosan was of high purity grade and free of any other biopolymers/inorganic content and pigments (content of proteins and other impurities $<0.5 \%$ ).

Since the particle size significantly affects the EBP-processing conditions (e.g., treatment time, rotation frequency of the reaction chamber), this parameter was additionally characterized obtained by SEM (FEI Quanta 200, FEI Company, Hillsboro, Oregon, USA), and the value $100 \pm 10 \mu \mathrm{m}$ was found. The additional $D D$ measurements by proton nuclear magnetic resonance $\left({ }^{1} \mathrm{H}-\mathrm{NMR}\right)$ revealed that $D D$ was $92.0 \pm 2.1 \%$. The chitosan powder to be the EBP-treated was preliminary dried in vacuum $10^{-3}$ Pa overnight to decrease the water content associated with polysaccharides molecules.

The chitosan powder was dried before treatment in vacuum $10^{-3}$ Pa overnight to decrease the water content associated with polysaccharides molecules. Then about $10 \mathrm{~g}$ of chitosan powder was put into the cylindrical reaction chamber (7), which was rotated by a stepper motor to mix chitosan during the treatment ensuring uniformity of the powder processing. The plasma generating gas was spectroscopic grade oxygen (Scientific Industrial Center of National Research Center "Kurchatov Institute", Moscow, Russia). Other processing conditions are given in Table 1 and the entire chitosan treatment procedure was described in more detail in [37].

\subsection{Characterization of the EBP-Treated Chitosan}

\subsubsection{Solubility Measurements}

Solubility measurements were carried out in accordance with the procedure described earlier [42].

\subsubsection{Molecular Weight Measurement}

The molecular masses (weight-average $M_{w}$, number-average $M_{n}$, and polydispersity $M_{w} / M_{n}$ ) of the EBP-treatment products were measured by size exclusion chromatography on a LC-20 Prominence HPLC system (Shimadzu, Kyoto, Japan), equipped with a refraction index detector RID-10A. The chromatographic column was Polargel-M $300 \times 7.5 \mathrm{~mm}$ (Agilent, Santa Clara, CA, USA). Other analysis conditions were as follows: mobile phase$0.1 \mathrm{M} \mathrm{NaCl}$ aqueous solution containing $0.01 \%$ trifluoroacetic acid; flow rate $-1.0 \mathrm{~mL} / \mathrm{min}$; temperature $-40^{\circ} \mathrm{C}$; volume of the injected sample $-20 \mu \mathrm{L}$; duration of the analysis $-20 \mathrm{~min}$. The concentration of chitosan solutions was $1.0 \mathrm{mg} / \mathrm{mL}$. Pullulans (Agilent, Santa Clara, CA, USA) with $M_{w}=340-45,500$ Da were used as standard samples (concentration of the solutions $1.0 \mathrm{mg} / \mathrm{mL}$ ) for the molecular weight calibration curve. The WinGPC software (PSS, Mainz, Germany) was applied to process the measured data.

\subsubsection{Transform Infrared Spectroscopy (FT-IR)}

IR spectral measurements in a wavenumber range $500-5000 \mathrm{~cm}^{-1}$ with a resolution of $4 \mathrm{~cm}^{-1}$ were carried out by a FT-IR spectrometer Perkin-Elmer Spectrum 100 (Perkin-Elmer, Waltham, MA, USA) as described in [37,42].

\subsubsection{Deacetylation Degree Measurement}

The chitosan samples for NMR-analysis were prepared as described in the literature [44,45]. Briefly, $5 \mathrm{mg}$ of chitosan powder was mixed with $600 \mu \mathrm{L}$ of $2 \%$ trifluoroacetic acid $/ \mathrm{D}_{2} \mathrm{O}$ solution. The trifluoroacetic acid was used as a solvent, since it has no proton signals in $\mathrm{D}_{2} \mathrm{O}$ and, thus, the region of the chitin/chitosan acetyl group in the ${ }^{1} \mathrm{H}$ NMR spectra ( 1.9 ppm) can be analyzed without any issues.

The deacetylation degree $(D D, \%)$ of the EBP-treated chitosan was measured as proposed $[44,45] .{ }^{1} \mathrm{H}$ NMR spectra of the chitosan oligosaccharides samples were recorded by a Bruker AVANCE III ${ }^{\mathrm{TM}} 600 \mathrm{MHz}$ instrument (Bruker, Billerica, MA, USA) at $25{ }^{\circ} \mathrm{C}$ 
using standard $5 \mathrm{~mm}$ probe. A standard single-pulse sequence with a pulse duration of $10.5 \mu$ s was used to record ${ }^{1} \mathrm{H}-\mathrm{NMR}$ spectra. The time of free induction decay was $3.6 \mathrm{~s}$; the delay between pulses was $1 \mathrm{~s}$. The width of the spectral range was $15 \mathrm{ppm}$, and the NMR spectra were averaged over 32 accumulations.

Then the average deacetylation degree of the EBP-treated chitosan was calculated from the relationship (1):

$$
D D(\%)=\left(1-\left(\frac{1}{3} I_{H-A c} /\left(\frac{1}{6} I_{H_{2}-H_{6}}\right)\right)\right) \times 100,
$$

where $I_{\mathrm{CH} 3}$ is the integral intensity of the acetyl group $(\mathrm{H}-\mathrm{Ac})$ and $I_{\mathrm{H} 2-\mathrm{H} 6}$ is the sum of the integral intensities of $I_{\mathrm{H} 2}, I_{\mathrm{H} 3}, I_{\mathrm{H} 4}, I_{\mathrm{H} 5}, I_{\mathrm{H} 6}$, and $I_{\mathrm{H} 6}$ protons [44]. The numbered scheme of the chitin/chitosan unit is given in Figure A1. The DD calculations based on the of the acetyl group are more accurate due to its high amplitude and resolution compared with the peak of $\mathrm{H} 1$.

\subsection{Bio-Activity of the EBP-Produced COS: Plant Experiments}

\subsubsection{Influence of the EBP-Produced COS on the Root Growth}

The effect of the EBP-produced COS on plant root growth was studied using Arabidopsis thaliana (Col-0), a popular model organism in plant biology. The scheme of the experiment is presented in Figure 3 and was based on a plant phenotyping platform published previously [46]. Surface sterilized Arabidopsis seeds were placed in Phytostrips (4titude Ltd., Wotton, UK) inserted into 96-well plates at a concentration of 6 to 12 seeds per well with Phytagel ${ }^{\mathrm{TM}}$ BioReagent (Sigma-Aldrich, Hamburg, Germany) and incubated at $4{ }^{\circ} \mathrm{C}$ overnight. Then the seeds were moved to the growth chamber for 3 days at temperature of $22 / 21{ }^{\circ} \mathrm{C}$ (day/night; $16 / 8 \mathrm{~h}$ ) and $70 \%$ relative humidity under light intensity of $120 \mu \mathrm{mol} /\left(\mathrm{m}^{2} \times \mathrm{s}\right)$. On the fourth day, $150 \mu \mathrm{L}$ of two different aqueous COS solutions produced after 5 and 10 min of EBP treatment were added to each well at two different concentrations ( 0.25 and $1 \mathrm{mg} / \mathrm{mL}$, respectively). The equal volume of distilled water was added to control plants. Three days later, the impact of the EBP-produced COS on the total root growth was assessed by measuring the longest primary root in each tube.

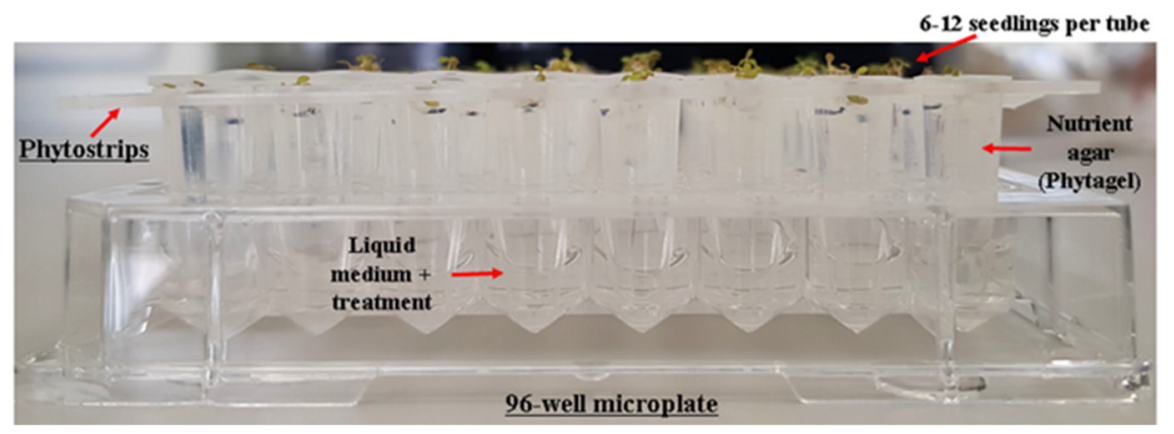

Figure 3. The effect of the EBP-produced chitooligosaccharide (COS) on Arabidopsis thaliana root growth: the scheme of the experiment.

\subsubsection{Greenhouse Trial: Biostimulating Effects of the EBP-Produced COS on Tomato Plants}

Tomato seeds (Lycopersicon esculentum, cv. Micro-Tom) were surface sterilized with sodium hypochlorite for $1 \mathrm{~min}$ before being thoroughly rinsed with distilled water. Seeds were set in plug trays using growth medium of compost: vermiculite: perlite $(5: 1: 1)$. Tomato seedlings were grown in a growth room at a temperature of $27 / 22 \pm 2{ }^{\circ} \mathrm{C}$ (day/night; $16 / 8 \mathrm{~h})$ and $70 \pm 5 \%$ relative humidity under light intensity of $80 \mu \mathrm{moL} /\left(\mathrm{m}^{2} \times \mathrm{s}\right)$. After 24 days, five tomato seedlings were randomly selected for treatment and transplanted to $2.5 \mathrm{~L}$ pots containing compost, vermiculite and perlite (6:1:1) placed $40-50 \mathrm{~cm}$ apart. Plants were fertilized twice at 30 day intervals with $2 \mathrm{~g} /$ pot of 7:7:7 $\left(\mathrm{N}_{2} \mathrm{P}_{2} \mathrm{O}_{5}: \mathrm{K}_{2} \mathrm{O}\right)$ at each time and irrigated with water every other day. The EBP-produced COS were dissolved 
in distilled water at $0.25 \mathrm{mg} / \mathrm{mL}$ and applied three times after transplanting by foliar spray $(1,25$, and 38 days, respectively). Control plants were sprayed with equal volume of distilled water. Potted plants were grown in a greenhouse at $23 \pm 7^{\circ} \mathrm{C}$ and $85 \%$ relative humidity. Reproductive parameters linked to crop yield, such as the average number of flowers (including flower buds and active flowers), and fruits per plant were measured weekly after transplant.

\subsection{Statistical Analysis}

The deacetylation degree measurements were performed by triplicate for the original chitosan and COS samples treated for 5 and $10 \mathrm{~min}$ and the standard deviations were then calculated $(N=3)$. Arabidopsis thaliana phenotypic assessment was done in three independent experiments (biological replicates) with at least twelve tubes per treatment $(N=36)$. Growing of tomato plants and phenotypic assessment was done in three independent experiments (biological replicates) with at least five plants per treatment $(N=15)$. Statistics were evaluated with the Statgraphics Centurion XVI software for Windows. Arabidopsis and tomato phenotypic differences between untreated and COS-treated tomato plants were analyzed with a one-way analysis of variance (ANOVA) [47]. The significance level was set at $p \leq 0.05$ and performed by Fisher's least significant difference (LSD) test. The graphical representation of the obtained data and their statistical significance were performed routinely in accordance with [48-50].

\section{Results and Discussion}

\subsection{Characterization of the EBP-Produced COS}

The EBP-produced COS were water-soluble up to $95 \%$ and the product yield ranged between 70 and $85 \%$ after optimizing the EBP-processing of the original chitosan powder [37]. Since the EBP affects the material surface layers about 20-30 $\mu \mathrm{m}$ in thickness, the water insoluble part of the final product can be the residual high molecular weight original chitosan that was not destructed by the plasma action. It should be reminded that the starting size of the chitosan particles was $100 \mu \mathrm{m}$.

In the present study, the relationship between COS water-solubility and EBP-treatment duration was confirmed and this relationship was valid for any mass of the chitosan powder. When the EBP-treatment duration exceeded a certain value (12 min under the conditions described in the current experimental design), the solubility of the formed COS decreased and a significant precipitation in water was observed. This could be the result from the secondary polymerization of formed COS (possibly due to the formation of Schiff bases).

Molecular masses and chemical structure of the COS produced by the EBP-stimulated degradation were characterized by size exclusion chromatography, FT-IR, and ${ }^{1} \mathrm{H}$ NMR. After 5 and 10 min of treatment conditions, the generated COS showed $M_{w}$ values of 1300 and $570 \mathrm{Da}$ with polydispersity index values of 1.6 and 1.5 , respectively (Table 2). The obtained results were in accordance with our previous investigation on the EBP-stimulated depolymerization of chitosan [37]. The FT-IR spectra of the EBP-treated chitosan and their detailed analysis can also be found in our paper [37]. Some increase of oxygen-containing carbonyl $\mathrm{C}=\mathrm{O}$ and carboxyl $-\mathrm{COOH}$ groups and some destruction of the $\beta$-1,4-glycosidic bonds were observed after chitosan processing in oxygen EBP.

The degree of deacetylation $(D D, \%)$ is a fundamental parameter influencing chemical and biological properties of chitosan and chitooligosaccharides including their plantstimulating activities [4]. Theoretically, pure chitin oligosaccharides should have a $D D=0 \%$ and pure chitosan oligosaccharides should have no acetylation $(D D=100 \%)$. However, commercial COS contains both $N$-acetylglucosamine and glucosamine residues because of their preparation methods $[14,15,51]$. 
Table 2. Physicochemical properties of the COS obtained from chitosan by the EBP-processing and conventional methods.

\begin{tabular}{|c|c|c|c|c|}
\hline \multirow{3}{*}{ Characteristic } & \multicolumn{4}{|c|}{ Method of the COS Production } \\
\hline & \multicolumn{2}{|c|}{ EBP-Processing } & \multirow{2}{*}{ Chemical Hydrolysis } & \multirow{2}{*}{ Enzyme Hydrolysis } \\
\hline & $5 \mathrm{~min}$ & $10 \mathrm{~min}$ & & \\
\hline Molecular weight $M_{w}, \mathrm{Da}$ & 1300 & 570 & Below $3900[14,15]$ & $\begin{array}{l}\text { The COS with degrees of } \\
\text { polymerization between } 2 \text { and } 20 \\
\text { (500-5000 Da) are produced, } \\
\text { depending on the hydrolysis } \\
\text { conditions and enzyme used [14,15] }\end{array}$ \\
\hline Polydispersity & 1.6 & 1.5 & $1.0-2.5[52]$ & $1.0-2.6[52]$ \\
\hline$D D, \%$ & $94.8 \pm 2.6$ & $96.0 \pm 2.7$ & $\begin{array}{l}\text { 96-98 depending on the hydrolysis conditions } \\
\text { and original chitosan characteristics [46] }\end{array}$ & $\begin{array}{l}\text { 58-99 depending on the hydrolysis } \\
\text { conditions and enzyme used [53] }\end{array}$ \\
\hline Water-solubility, $\%$ & 95 & 95 & $90-100[14,15]$ & $90-100[14,15]$ \\
\hline
\end{tabular}

The ${ }^{1} \mathrm{H}$ NMR spectra of the original chitosan and COS are given in Figure A1. The most specific signals from the ${ }^{1} \mathrm{H}$ NMR spectrum of the original chitosan manufactured by Bioprogress Co. (Russia) were the second proton of $D$-glucosamine unit and the acetate group proton of $N$-acetyl- $D$-glucosamine. Therefore, a $D D$ of $92.0 \pm 2.1 \%$ was estimated according to the proposed methodology $[44,45]$. The ${ }^{1} \mathrm{H}$ NMR analysis of the generated COS revealed the $D D$ was slightly increased after the EBP processing step. The calculated $D D$ values were $94.8 \pm 2.6 \%$ and $96.0 \pm 2.7 \%$ for chitosan treated for 5 and $10 \mathrm{~min}$ respectively (Table 2).

\subsection{Plant Bioactivity of the EBP-Produced COS}

To evaluate the capacity for the plant root growth stimulation induced by the EBPproduced COS, the generated treatments were applied to the micro-phenotyping system wells at two different concentrations when Arabidopsis thaliana seeds began to germinate (fourth day in the growth room). After 3 days, a positive effect on total root growth was evident in all COS-treated seedlings compared to the untreated ones. The application of the EBP-produced COS after $5 \mathrm{~min}$ of treatment at 0.25 and $1 \mathrm{mg} / \mathrm{mL}$ resulted in a statistically significant root growth increase, exhibiting values from $33 \%$ to $40 \%$ higher, with respect to the untreated seedlings. In contrast, the root growth promotion effect was lower when the COS produced after $10 \mathrm{~min}$ of the EBP treatment were applied to the liquid growing medium. A similar growth promotion effect was found when barley plants were irrigated with low doses of chitosan $(0.01$ and $0.1 \mathrm{mg} / \mathrm{mL})$ [54]. However, a reduction of the root length was observed when different crops were grown after applying commercial COS or medium molecular weight chitosan at concentrations higher than $0.5 \mathrm{mg} / \mathrm{mL}$ [7]. Several authors demonstrated that the molecular weight and deacetylation degree of the COS can affect their biological activities [4,51]. Our results suggest that both physicochemical parameters (determined by the duration of the EBP treatment) and the applied COS concentration also have an important role in modulating the rooting system.

Foliar application of both EBP-produced COS formulations at $0.25 \mathrm{mg} / \mathrm{mL}$ to tomato plants (cv. Micro-Tom) also altered two important plant productivity indicators compared to untreated plants. Being treated by COS, the plants demonstrated the extended flowering time and significant increase in the average number of flowers per plant (determined as the sum of bud and active flowers after the application of the second and third foliar spray, performed 25 and 37 days after transplant), at 38 days after transplant (from 16\% to 36\%), with respect to the control ones. The EBP-produced COS after $10 \mathrm{~min}$ of treatment also increased the average number of flowers although this increase was bigger at later growth stages (Figure 4). A stimulating effect of the chitosan and COS on the number of flowers was observed previously in plants $[2,4,8]$. However, in some of these studies, the treated plants flowered 10 and 15 days earlier than the control plants [8]. Therefore, it might be useful to use the EBP-produced COS over different horticulture crops to obtain a higher number of flowers for a longer time, enhancing the fruit set possibility. 


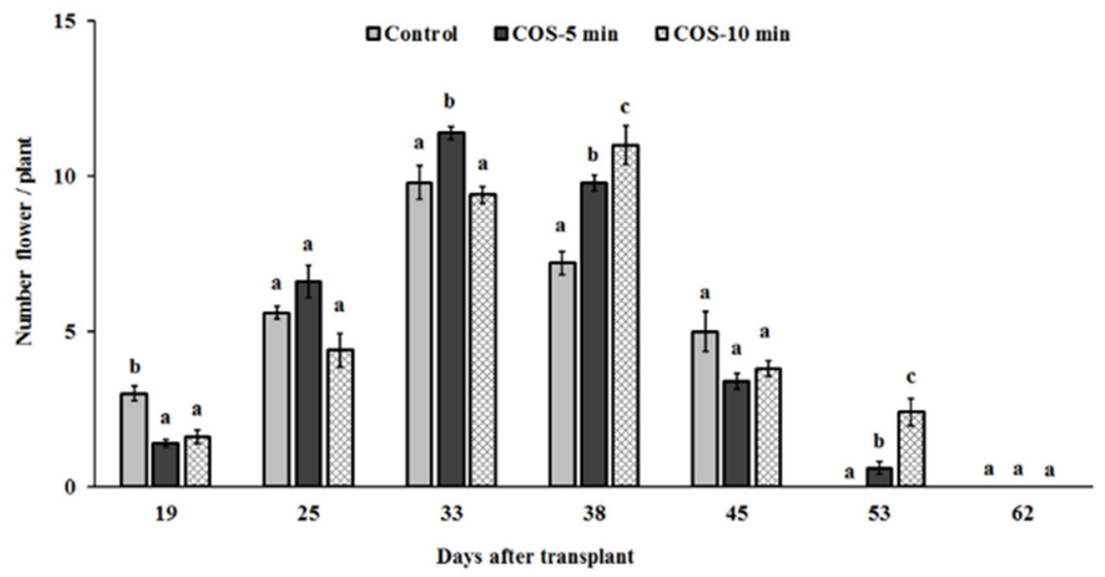

Figure 4. The effect of the EBP-produced COS on flower number in tomato plants (cv. MicroTom). Treatments were applied three times after transplanting by foliar spray at $0.25 \mathrm{mg} / \mathrm{mL}(1$, 25 , and 37 days, respectively). The data are presented as Means \pm SE. The same letters within the same time point indicate that there are no statistically significant differences between the data. For example, for day 33, a statistically significant increase ( $p \leq 0.05$, Fisher's LSD test) is observed only for COS-5 min (marked as b), and for control and COS-10 (marked as a) there are no statistically significant differences.

The stimulating effect of the EBP-COS on the increase in the fruits number was statistically confirmed at the later growth stage. Moreover, 62 days after the transplant, tomato plants treated with the COS produced after 5 and 10 min of the EBP treatment yielded $11.9 \%$ and $16.7 \%$ more fruits, respectively (Figure 5 ). The effect of COS produced in the EBP is comparable with that of COS obtained by means of other techniques $[4,9,55-58]$. As a result of applying a water-soluble formulation of chitosan oligosaccharides, four times at $0.25 \mathrm{mg} / \mathrm{mL}$, the marketable fruit yield of the industrial tomato cultivar "H9661" increased between $9 \%$ and $19 \%$, with respect to the control [9]. Moreover, application of 500 $\mathrm{mg} / \mathrm{mL}$ water-soluble commercial chitosan in vitro resulted in improved acclimatization of potato plantlets in the greenhouse and significantly increased the average tuber number by $36 \%$ compared to the untreated plants [55].

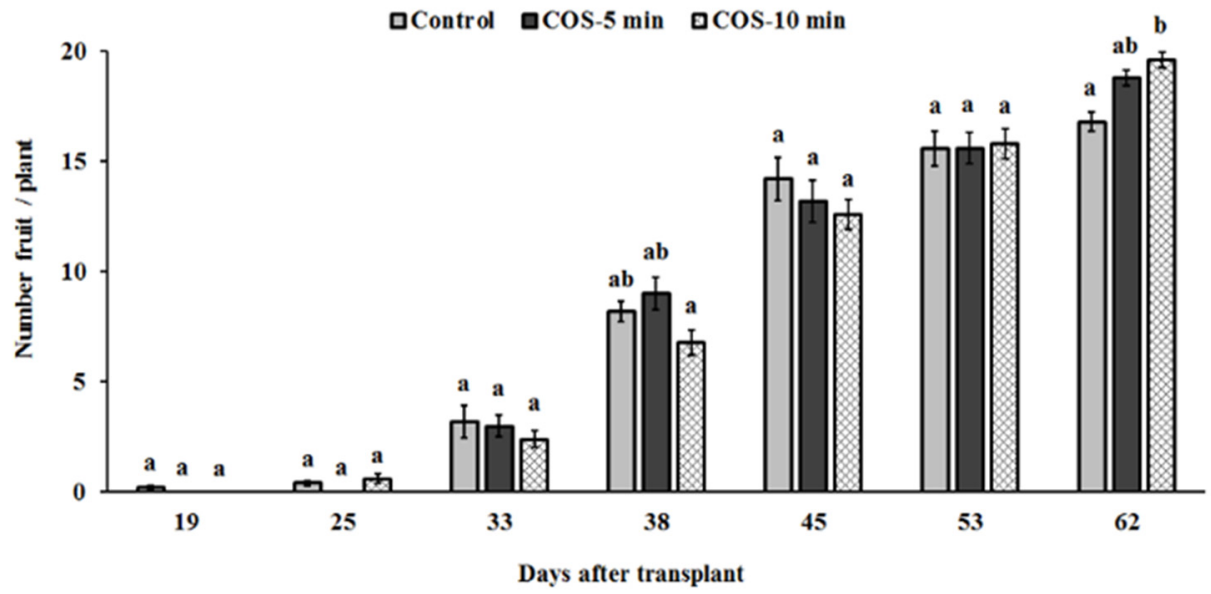

Figure 5. The effect of the EBP-produced COS on fruit number in tomato plants (cv. Micro-Tom). Treatments were applied three times after transplanting by foliar spray at $0.25 \mathrm{mg} / \mathrm{mL}(1,25$, and 37 days, respectively). Means $\pm \mathrm{SE}$ followed by different small letter within the same time point indicate significant differences between treatments based on Fisher's LSD test $(p \leq 0.05)$. The labeling principle of columns (a or $\mathbf{b}$ ) is the same as in Figure 4. 


\subsection{Possible Mechanisms of the EBP-Action on Chitosan}

The following EBP factors can affect the polysaccharides structure, and chitosans among them, when they are processed in the EBP:

- Chemically active heavy particles of the EBP: excited molecules and atoms, ions, radicals, e.g., active oxygen species;

- Fast electrons of the partially degraded EB that bombard material;

- Secondary electrons of moderate energies $(0.01-1 \mathrm{keV})$ produced in the EBP due to ionization of the plasma generating media molecules;

- The EBP-radiation, especially UV and X-ray (bremsstrahlung);

- Possible heating by direct electron bombardment and due to heat transfer between the plasma cloud and sample.

Each of these factors is able to cause transformations of polymeric molecules, but the integral effect of the polysaccharides macro-molecule modification is likely to be due to their joint action (i.e., synergism is expected to take place).

The EBP composition is complex; generally, it contains molecules, atoms, radicals, and ions in stable and excited states; plasma electrons and electrons of the injected beam are present as well. These particles can stimulate many physical and chemical processes on the surface and in the bulk of the matter inserted into the plasma cloud. Our previous studies showed the plasma chemical processes to predominate when biopolymer materials, chitosan, and some other polysaccharides among them, are affected by the EBP [37,39]. In oxygen-containing plasma generating media the active oxygen particles $(\mathrm{O}$, singlet oxygen), and especially hydroxyl radicals $\mathrm{OH}^{\bullet}$ formed in plasma chemical reactions are the most important for the chitosan depolymerization and COS production [59]. The $\mathrm{OH}^{\bullet}$ radicals can be formed due to the plasmolysis of both water molecules associated with original polysaccharides and water eliminated in the EBP-stimulated dehydration of chitosan $\beta$ 1,4 -glycosidic bonds. In our experiments, the mass-spectrometer always detected water in oxygen-containing atmosphere when chitosan was plasma chemically processed.

It was shown that the $\mathrm{OH}^{\bullet}$ radicals react with carbohydrates extremely rapidly $\left(k=1-4 \mathrm{nM}^{-1} \cdot \mathrm{s}^{-1}\right)$ [60], abstracting hydrogen atoms at all ring $\mathrm{C}-\mathrm{H}$ bonds in carbohydrates except $\mathrm{C}-2$ of $\mathrm{N}$-acetyl hexosamine according to scheme [61]:

$$
\mathrm{RH}+\mathrm{OH}^{\bullet} \rightarrow \mathrm{R}^{\bullet}+\mathrm{H}_{2} \mathrm{O}
$$

Oxidation changes in the polysaccharides molecules with increase of carbonyl $\mathrm{C}=\mathrm{O}$ and carboxyl-COOH groups after the treatment in the EBP of oxygen also support this hypothesis.

The second pathway that leads to the depolymerization is the interaction of polysaccharides chains with atomic oxygen that reacts fast with various carbonaceous materials [62]. The importance of atomic oxygen species compared to that of excited atomic or molecular nitrogen species was confirmed in studies of isolation of chitin biopolymer from waste crustacean biomass and chitosan degradation/gelation in the RF low-pressure discharge, atmospheric-pressure dielectric barrier discharge, and in the liquid-phase plasma systems [35,62-66].

As reported in our papers [37,38], and in literature [61], the reaction involves the abstraction of the hydrogen atom with the generation of carbon-center radicals at all ring $\mathrm{C}-\mathrm{H}$ bonds in chitosan (except $\mathrm{C}-2$ of $\mathrm{N}$-acetyl hexosamine) and a $\beta$-scission reaction resulting in the breakdown of polysaccharide chains.

\subsection{Advantages and Power Efficiency of the COS Production in EBP-Assisted Processes in Comparison with Conventional Methods}

As mentioned in the introduction, the chitosan processing in the EBP is, absolutely, a dry process: dry low molecular weight products are downloaded from the reactor after plasma chemical treatment of the original chitosan powder. Only non-toxic gases (oxygen, water vapor, or their mixtures) are used as plasma generating medium and no technological liquids, such as solvents or reactants, are required. 
Nowadays, chitin and chitosan deacetylation is obtained commercially by heating their solutions in strong alkali at high temperatures. These harsh conditions are responsible for several drawbacks of these technologies such as environmental pollution or the randomness of the chemical reactions [67]. As an advanced alternative, the application of enzymatic de-N-acetylation by using chitin deacetylases (CDAs) has been proposed [68]. Although some CDAs have been characterized in detail, their commercial availability is limited. In contrast with them, chitosan depolymerization-deacetylation in the EBP seems to be quick, direct environmental friendly process of chitosan powder treatment without any solution preparing, product extraction, and drying.

The most relevant characteristics of COS produced in the EBP, and by conventional methods (by chemical and enzyme hydrolysis), are compared in Table 2. It should be noted that the EBP processing did not only effectively depolymerize chitosan polysaccharides, but also slightly enhanced the deacetylation of the produced COS.

Known mechanochemical processes of polymers modification (e.g., shaking at sonic or ultrasonic frequencies) occur in solutions or in suspension. Therefore, additional procedures are necessary to prepare raw materials and extract the target product. As to microwave facilities potentially applicable for chitosan processing, they are conventionally used for heating, drying, defrosting, or decontamination of biopolymers. Non-thermal microwave action is effective for thermoplastic and thermosetting dielectrics only. Controllable microwave-assisted chitosan processing has to be carried out in water, hydrogen peroxide, or some other polar liquids $[16,69,70]$. Besides, in setups for non-thermal polymer processing, only a small part of the microwave power is used and special ballast loads are required to absorb the main part of it. Complicated matching devices have to be applied to protect the microwave generator from the back mode, reflected by the reaction chamber, ballast load, and waveguide. Obviously, the above significantly increases power consumption and reduces economy efficiency of possible chitosan mechanochemical and MW-processing [71-73].

Table 3 presents the comparison of the COS production in the beam-plasma reactors with conventional chemical and enzymatic hydrolyses in terms of basic treatment process characteristics, yield, and environmental safety.

Table 3. The comparison of the EBP-stimulated chitosan destruction with conventional methods.

\begin{tabular}{|c|c|c|c|c|c|}
\hline Criteria & & Chemical Hydrolysis & & $\begin{array}{l}\text { Enzymatic } \\
\text { Hydrolysis }\end{array}$ & EBP-Processing \\
\hline Treatment duration & & Several hours or days & & Several hours & Minutes $(\tau=2-10)$ \\
\hline Number of stages & & Multi-stage & & Multi-stage & Single-stage \\
\hline $\begin{array}{l}\text { Specificity and } \\
\text { efficiency }\end{array}$ & $\begin{array}{l}\text { (1) } \\
(2) \\
(3)\end{array}$ & $\begin{array}{l}\text { Destruction of } \\
\beta-1,4 \text {-glycosidic bounds; } \\
\text { Predominant destruction of } \\
\text { amorphous parts of biopolymer; } \\
\text { Possible oxidation changes in } \\
\text { produced oligosaccharides and } \\
\text { deep oxidation of original } \\
\text { biopolymers [51,52]. }\end{array}$ & $\begin{array}{l}(1) \\
(2) \\
(3) \\
(4)\end{array}$ & $\begin{array}{l}\text { Specific, easy to control (including the } M_{w} \\
\text { distribution of the product); } \\
\text { Different binding affinities for chitosan of } \\
\text { various enzymes and multiphasic kinetics } \\
\text { of reactions results in the formation of } \\
\text { product mixtures }[14,15] ; \\
\text { The action of enzymes is affected } \\
\text { by the degree of deacetylation and } \\
\text { the polymerization degrees } \\
\text { of original chitosan; } \\
\text { Generated products show broader } M_{\mathrm{w}} \\
\text { ranges, which can provide multiple } \\
\text { bioactive effects }[14,15,51] \text {. }\end{array}$ & $\begin{array}{ll}\text { (1) } & \begin{array}{l}\text { Destruction of } \\
\beta-1,4 \text {-glycosidic bounds; }\end{array} \\
\text { (2) } & \begin{array}{l}\text { Destruction of both amorphous } \\
\text { and crystalline parts of } \\
\text { biopolymer occurs; }\end{array} \\
\text { (3) } & \begin{array}{l}\text { Oxidation of oligosaccharides } \\
\text { (formation of } \mathrm{C}=\mathrm{O} \text { and }\end{array} \\
\text {-COOH groups); } \\
\text { (4) } \\
\text { Specific low molecular weight } \\
\text { COS are generated. }\end{array}$ \\
\hline COS yields & & $\begin{array}{l}\text { ow yields of COS and large amounts } \\
\text { of monomeric units [53]. }\end{array}$ & & Up to $90-95 \%[14,15,51]$ & Up to $80-85 \%$. \\
\hline Environment safety & $\begin{array}{l}(1) \\
(2) \\
(3)\end{array}$ & $\begin{array}{l}\text { Adverse environmental impact; } \\
\text { High energy consumption; } \\
\text { Produced oligomers are generally } \\
\text { considered unsafe bioactive materials } \\
\text { because of their possible } \\
\text { contamination with toxic chemical } \\
\text { compounds [53]. }\end{array}$ & & $\begin{array}{l}\text { Environmentally friendly. However, } \\
\text { diluted acidic and alkaline solution } \\
\text { may be needed }[14,34] \text {. }\end{array}$ & $\begin{array}{l}\text { Environmentally friendly. } \\
\text { Hazardous by-products and toxic } \\
\text { wastes are not generated. }\end{array}$ \\
\hline
\end{tabular}


Three particular problems are usually considered to enhance the EBP reactor efficiency:

- Efficiency of the electric power conversion into the electron beam power;

- Power loss in the injection window;

- Utilization efficiency of the injected EB, i.e., the ratio of the power directly used in material treatment to the total power of the EB injected into the reaction chamber.

Modern electron accelerators and electron guns are known to effectively convert the electric power into the electron beam power. Depending on the field of applications and design, they are able to transform up to $90 \%$ and more of supplied energy into the energy of the accelerated electrons flow. Guns with so called "plasma emitters" are preferable for plasma chemical reactors, but conventional devices with thermionic emitters are quite competitive. So far, the thermionic guns remain more powerful and they can generate thinner beams. This option is valuable when the beam is transported into the reaction chamber through the channels of the gas-dynamic windows used in the present research.

Electron power loss mainly depends on the pressure distribution, initial electron energy, and temperature of the gas through which the beam propagates. In its turn, the gas temperature depends on the beam parameters (current, electron energy, and beam diameter) and gas pressure. Thus, the design of every IW should be optimized in accordance with plasma generating gas composition, required pressure in the reaction chamber, and characteristic temperature of the treatment process. Under typical experimental conditions (Table 1), our power loss in the IW did not exceed $25 \%$ of the original beam power. For a greater clarity, energy losses at various stages of the energy transformation are shown in Figure 6.

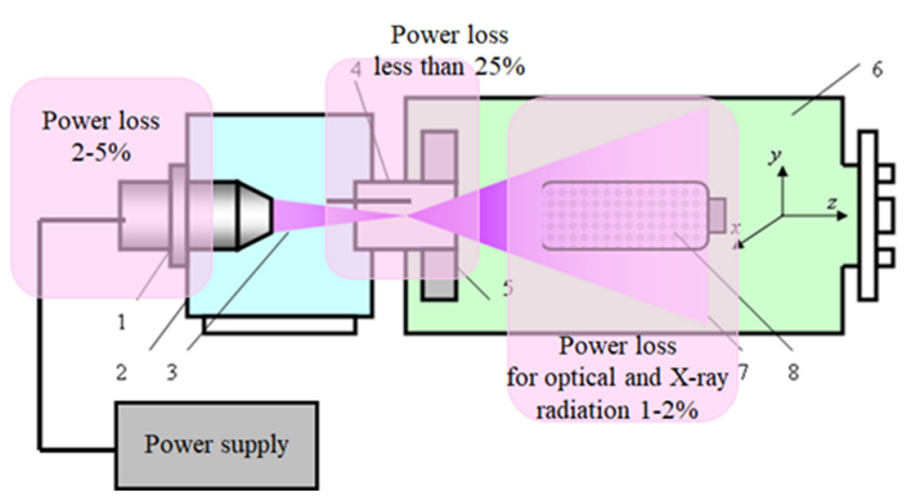

Figure 6. Some estimations of Electron Beam-Plasma Reactors efficiency: 1-electron-beam gun, 2-high vacuum chamber, 3-electron beam, 4-injection window, 5-electromagnetic scanning system, 6-working chamber, 7-EBP cloud, 8-mixer with polysaccharide powder to be treated.

Only $1-2 \%$ of the injected beam power is transformed in related processes, such as emission of optical and X-ray radiation or secondary electron emission, and some others. The main portion of the injected beam power is used to produce chemically active plasma particles, to keep desirable material temperature, and to support the reactor operation (e.g., for the IW operation). Thus, the reactors power efficiency is sufficiently high and competitive when compared to the best conventional chemical reactors. Beam-plasma reactors do not usually exhaust any hazardous liquids and toxic gases, which gives them additional advantages from the point of view of environment safety.

Some estimations of the cost/availability of EBP and the operation/maintenance costs of such a system are given in Appendix B.

In general, beam-plasma reactors, both prototypes described (Figure 1), and the industrial version under development can be assembled from units available on the market, and only the window for the electron beam injection is a unique component of the reactor design. The EBP generator and its supporting systems are not more expensive than equipment conventionally used for chemical or biochemical chitosan processing. Considering that no raw materials and solution preparation, exhausts cleaning, product separation, and 
some other procedures are required, manufacturing and operation of the beam-plasma reactor are cheaper than those of traditional processes and equipment for COS production.

\section{Conclusions}

In general, plasmachemical technologies based on the EBP can be considered effective, resource saving, and environmentally friendly alternatives to the conventional industrial processing methods used for natural polysaccharides, such as chitin, chitosan, cellulose, and others. The data presented have demonstrated that very specific low molecular weight COS, obtained by the short time EBP treatment, can stimulate important plant related productivity parameters (root length, number of flowers, and fruits) and open new possibilities for production of bioactive water-soluble COS for agricultural applications.

Author Contributions: Conceptualization, T.V. and O.G.; methodology, T.V., O.G., P.Q., and D.K.; software, P.Q.; validation, T.V., O.G., P.Q., and N.U.; formal analysis, T.V., O.G., P.Q., S.S., and N.U.; investigation, T.V., O.G., P.Q., S.S., and N.U.; resources, T.V., S.O., O.G., D.K., and M.V.; data curation, T.V., O.G., and D.K.; writing-T.V., O.G.; writing-review and editing, O.G. and M.V.; visualization, T.V., O.G., P.Q., and S.S.; supervision, T.V., O.G., S.O., and M.V.; project administration, S.O., D.K., and M.V.; funding acquisition, T.V. and M.V. All authors have read and agreed to the published version of the manuscript.

Funding: This research was funded by the Russian Foundation for Basic Research, grant numbers 19-38-90009 and 20-02-00501_a.

Informed Consent Statement: Not applicable.

Data Availability Statement: The data presented in this study are available in this manuscript, https://doi.org/10.3390/xxxxx.

Acknowledgments: The analytical instrumentation of the Core Facility Center "Arktika" of Northern (Arctic) Federal University was partially used to characterize the COS obtained in the present research. The Center "Arktika" is financially supported by the Ministry of Education and Science of Russian Federation.

Conflicts of Interest: The authors declare no conflict of interest.

\section{Appendix A}

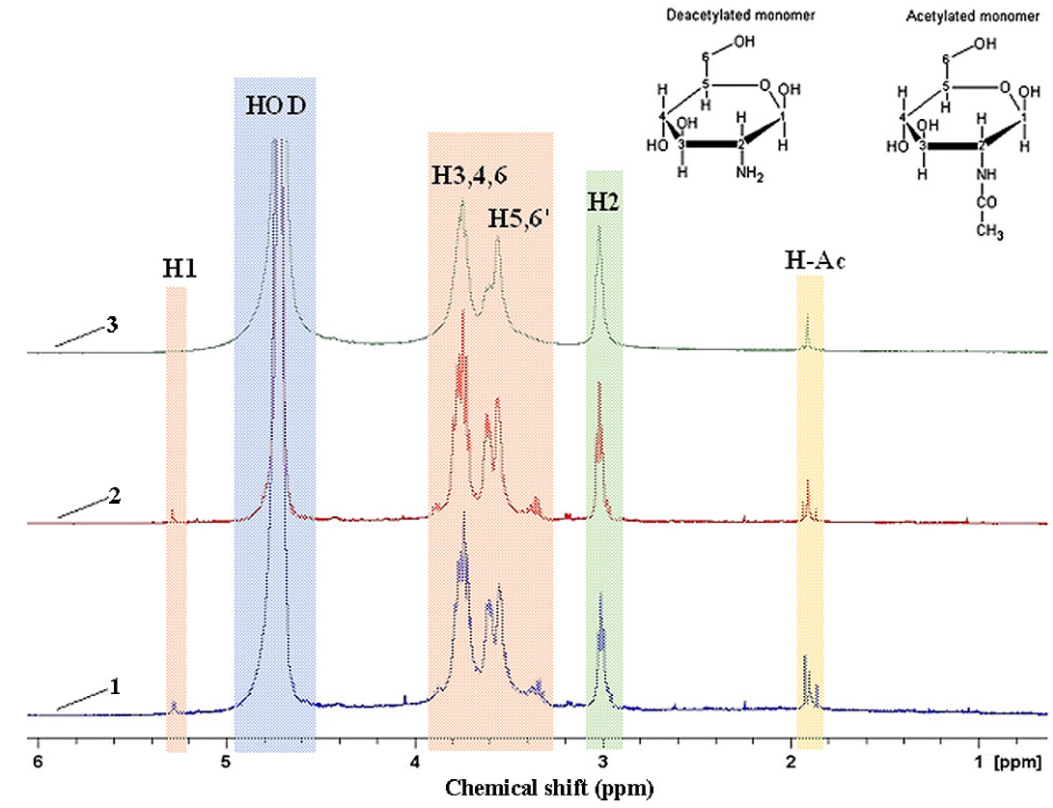

Figure A1. The ${ }^{1} \mathrm{H}$ NMR spectrum of the original chitosan (1) and chitosan treated in oxygen EBP for $5 \mathrm{~min}$ (2) and $10 \mathrm{~min}$ (3). The scheme of the protons in the chitin/chitosan unit is also included in the figure. 


\section{Appendix B}

Table A1. The availability and the maintenance of EBP-systems.

\begin{tabular}{|c|c|c|c|c|}
\hline $\begin{array}{c}\text { Beam-Plasma Generator } \\
\text { Part }\end{array}$ & Unit Version & Weight, kg & Product Manufacturer & Maintenance \\
\hline \multirow[t]{2}{*}{ Electron gun } & Thermionic cathode $\mathrm{LaB}_{6}$ & $\approx 10$ & $\begin{array}{l}\text { Numerous manufacturers of } \\
\text { welding electron guns, e.g., } \\
\text { PROGRESS Company, Russia }\end{array}$ & $\begin{array}{l}\text { Lifetime more than } 100 \mathrm{~h} \\
\text { under normal conditions }\end{array}$ \\
\hline & Plasma cathode & $\approx 8$ & TUSUR University, Russia & Unlimited lifetime \\
\hline $\begin{array}{l}\text { High voltage power } \\
\text { source }\end{array}$ & $\begin{array}{l}\text { High voltage generators of } \\
\text { positive or negative polarity }\end{array}$ & $\approx 15$ & $\begin{array}{c}\text { Spellman High Voltage } \\
\text { Electronics Corporation, USA }\end{array}$ & No maintenance \\
\hline \multirow[t]{2}{*}{ Beam control units } & $\begin{array}{l}\text { Controller of the beam power } \\
\text { (semi-automatic) }\end{array}$ & $\approx 20$ & TUSUR University, Russia & No maintenance \\
\hline & $\begin{array}{l}\text { Controllers of the beam power } \\
\text { and beam scanning (automatic) }\end{array}$ & $\approx 25$ & TUSUR University, Russia & No maintenance \\
\hline \multirow[t]{2}{*}{ Injection window } & Gas-dynamic window & $\approx 2$ & $\begin{array}{l}\text { Moscow Institute of Physics } \\
\text { and Technology, Russia }\end{array}$ & Lifetime about $100 \mathrm{~h}$ \\
\hline & $\begin{array}{l}\text { Gas-dynamic window with a } \\
\text { differential pumping stage }\end{array}$ & $\approx 5$ & $\begin{array}{l}\text { Moscow Institute of Physics } \\
\text { and Technology, Russia }\end{array}$ & Lifetime about $200 \mathrm{~h}$ \\
\hline \multirow[t]{2}{*}{ High vacuum system } & $\begin{array}{l}\text { Diffusion pump in combination } \\
\text { with oil sealed pump }\end{array}$ & $\approx 35$ & VACMA, Russia & Minimal maintenance \\
\hline & $\begin{array}{l}\text { Turbo molecular pump with } \\
\text { dry scroll pump }\end{array}$ & $\approx 35$ & $\begin{array}{l}\text { Numerous manufacturers, e.g., } \\
\text { STP Maglev with XDS, } \\
\text { Edwards Vacuum, UK }\end{array}$ & No maintenance \\
\hline Total weight & & 90-100 & & \\
\hline
\end{tabular}

As it was described in Section 2.1 the beam-plasma reactor consists of two main parts, namely the Beam-Plasma Generator and the reaction chamber. The reaction chambers were designed for various powder loadings, but all of them only slightly differ from available chambers conventionally used in electron-beam or plasma technologies by specific inner facilities and/or outer systems. The Beam-Plasma Generator is a unique device that we originally developed for aerospace applications on-board. It is compact, light, and simple for maintenance; the basic plasma generator configuration and its operation characteristics are described in [74]. This configuration is applicable for industrial purposes but a vacuum system is required to support electron gun operation and the injection window becomes more sophisticated [75]. Table A1 illustrates mass characteristics, availability, and specific maintenance of the main parts of the industrial beam-plasma generator $6 \mathrm{~kW}$ in power. The electrons energy (accelerating voltage of the electron gun) was limited by $50 \mathrm{kV}$ to simplify the protection against soft $\mathrm{X}$-ray radiation generated when the electron gun operates. Estimated Beam-Plasma Generator cost in basic configuration is about USD $\$ 200,000$. If the reactor must be multifunctional and adjustable to carry out a set of various plasma technological functions more complicated and, therefore, more expensive configurations have to be used. It should be mentioned that in the reactor scaling for higher loading the total equipment cost may significantly rise but the plasma generator cost rises much slower than the reaction chamber one.

\section{References}

1. Olicon-Hernandez, D.R.; Zepeda-Giraud, L.F.; Guerra-Sanchez, G. Current applications of chitosan and chitooligonaccharides. A review. J. Drug Des. Res. 2017, 4, 1039.

2. Liaqat, F.; Eltem, R. Chitooligosaccharides and their biological activities: A comprehensive review. Carbohydr. Polym. 2018, 184, 243-259. [CrossRef]

3. Xing, R.; Liu, Y.; Li, K.; Yu, H.; Liu, S.; Yang, Y.; Chen, X.; Li, P. Monomer composition of chitooligosaccharides obtained by different degradation methods and their effects on immunomodulatory activities. Carbohydr. Polym. 2017, 157, 1288-1297. [CrossRef]

4. Malerba, M.; Cerana, R. Chitosan effects on plant systems. Int. J. Mol. Sci. 2016, 17, 996. [CrossRef] 
5. Maruyama, C.R.; Guilger, M.; Pascoli, M.; Bileshy-Jose, N.; Abhilash, P.C.; Fraceto, L.F.; de Lima, R. Nanoparticles based on chitosan as carriers for the combined herbicides imazapic and imazapyr. Sci. Rep. 2016, 6, 19768. [CrossRef]

6. Mondal, M.M.A.; Malek, M.A.; Puteh, A.B.; Ismail, M.R.; Ashrafuzzaman, M.; Naher, L. Effect of foliar application of chitosan on growth and yield in okra. Aust. J. Crop Sci. 2012, 6, 918-921.

7. Chatelain, P.G.; Pintado, M.E.; Vasconcelos, M.W. Evaluation of chitooligosaccharide application on mineral accumulation and plant growth in Phaseolus vulgaris. Plant Sci. 2014, 215, 134-140. [CrossRef]

8. Salachna, P.; Zawadzinska, A. Effect of chitosan on plant growth, flowering and corms yield of potted. J. Ecol. Eng. 2014, 15, 97-102.

9. Goñi, O.; Quille, P.; O'Connell, S. Production of chitosan oligosaccharides for inclusion in a plant biostimulant. Pure Appl. Chem. 2016, 88, 881-889. [CrossRef]

10. Wang, M.; Chen, Y.; Zhang, R.; Wang, W.; Zhao, X.; Du, Y.; Yin, H. Effects of chitosan oligosaccharides on the yield components and production quality of different wheat cultivars (Triticum aestivum L.) in Northwest China. Field Crop Res. 2015, 172, 11-20. [CrossRef]

11. Kananont, N.; Pichyangkura, R.; Chanprame, S.; Chadchawan, S.; Limpanavech, P. Chitosan specificity for the in vitro seed germination of two Dendrobium orchids (Asparagales: Orchidaceae). Sci. Hortic. 2010, 124, 239-247. [CrossRef]

12. Vasconcelos, M.W. Chitosan and chitooligosaccharide utilization in phytoremediation and biofortification programs: Current knowledge and future perspectives. Front. Plant Sci. 2014, 5, 616. [CrossRef] [PubMed]

13. Nwe, N.; Furuike, T.; Tamura, H. Marine Biomaterials: Characterization, Isolation and Applications; Kim, S., Ed.; CRC Press, Taylor and Francis Group: Boca Raton, FL, USA, 2013; Chapter 4. [CrossRef]

14. Mourya, V.K.; Inamdar, N.N.; Choudhari, Y.M. Chitooligosaccharides: Synthesis, characterization and applications. Polym. Sci. Ser. A 2011, 53, 583-612. [CrossRef]

15. Zargar, V.; Asghari, M.; Dashti, A. A review on chitin and chitosan polymers: Structure, chemistry, solubility, derivatives, and applications. ChemBioEng. Rev. 2015, 2, 204-226. [CrossRef]

16. Kaczmarek, M.B.; Struszczyk-Swita, K.; Li, X.; Szczesna-Antczak, M.; Daroch, M. Enzymatic modifications of chitin, chitosan, and chitooligosaccharides. Front. Bioeng. Biotechnol. 2019, 7, 243. [CrossRef]

17. Ríos, A.G.D. Technical and Economic Feasibility Analysis of a Plant Process for Production of Chitosan from Shrimp Shells in Colombia. Master's Thesis, University of Antioquia, Medellín, Colombia, 2015.

18. Gortari, M.C.; Hours, R.A. Biotechnological processes for chitin recovery out of crustacean waste: A mini-review. Electron. J. Biotechnol. 2013, 16, 14 .

19. Philibert, T.; Byong, H.; Lee, B.H.; Fabien, N. Current status and new perspectives on chitin and chitosan as functional biopolymers. Appl. Biochem. Biotechnol. 2017, 181, 1314-1337. [CrossRef] [PubMed]

20. Jung, W.J.; Park, R.D. Bioproduction of chitooligosaccharides: Present and perspectives. Mar. Drugs 2014, 12, 5328-5356. [CrossRef]

21. Puac, N.; Gherardi, M.; Shiratani, M. Plasma agriculture: A rapidly emerging field. Plasma Processes Polym. 2017, 15, e1700174. [CrossRef]

22. Misra, N.N.; Schluter, O.; Cullen, P.J. Cold Plasma for Food and Agriculture: Fundamentals and Applications; Elsevier: London, UK, 2016.

23. Meng, Y.; Qu, G.; Wang, T.; Sun, Q.; Liang, D.; Hu, S. Air atmospheric dielectric barrier discharge plasma induced germination and growth enhancement of wheat seed. Plasma Chem. Plasma Process. 2017, 37, 1621-1634. [CrossRef]

24. Gomez-Ramirez, A.; Lopez-Santos, C.; Cantos, M.; Garcia, J.L.; Molina, R.; Cotrino, J.; Espinos, J.P.; Gonzalez-Elipe, A.R. Surface chemistry and germination improvement of Quinoa seeds subjected to plasma activation. Sci. Rep. 2017, 7, 5924. [CrossRef]

25. Brandenburg, R.; Bogaerts, A.; Bongers, W.; Fridman, A.; Fridman, G.; Locke, B.R.; Miller, V.; Reuter, S.; Schiorlin, M.; Verreycken, T.; et al. White paper on the future of plasma science in environment, for gas conversion and agriculture. Plasma Processes Polym. 2018, 16, e1700238. [CrossRef]

26. Shi, H.; Cooper, B.; Stroshine, R.L.; Ileleji, K.E.; Keener, K.M. Structures of degradation products and degradation pathways of Aflatoxin B1 by high-voltage atmospheric cold plasma (HVACP) treatment. J. Agric. Food Chem. 2017, 65, 6222-6230. [CrossRef]

27. Jampala, S.N.; Manolache, S.; Gunasekaran, S.; Denes, F.Z. Plasma-enhanced modification of xanthan gum and its effect on rheological properties. J. Agric. Food Chem. 2005, 53, 3618-3625. [CrossRef]

28. Dong, S.; Wang, J.; Cheng, L.; Lu, Y.; Li, S.; Chen, Y. Behavior of zein in aqueous ethanol under atmospheric pressure cold plasma treatment. J. Agric. Food Chem. 2017, 65, 7352-7360. [CrossRef]

29. Kim, T.H.; Lee, J.; Kim, H.J.; Jo, C. Plasma-induced degradation of quercetin associated with the enhancement of biological activities. J. Agric. Food Chem. 2017, 65, 6929-6935. [CrossRef] [PubMed]

30. Yin, S.; Ren, L.; Wang, Y. Argon plasma-induced graft polymerization of PEGMA on chitosan membrane surface for cell adhesion improvement. Plasma Sci. Technol. 2013, 15, 1041-1046. [CrossRef]

31. Pankaj, S. Cold Plasma Treatment of Biodegradable Films and Smart Packaging. Ph.D. Thesis, Dublin Institute of Technology, Dublin, Ireland, 2015.

32. Vosmanská, V.; Kolářová, K.; Rimpelová, S.; Kolská, Z.; Švorčík, V. Antibacterial wound dressing: Plasma treatment effect on chitosan impregnation and in situ synthesis of silver chloride on cellulose surface. RSC Adv. 2015, 5, 17690-17699. [CrossRef]

33. Nikitin, D.; Lipatova, I.; Naumova, I.; Sirotkin, N.; Pleskunov, P.; Krakovský, I.; Khalakhan, I.; Choukourov, A.; Titov, V.; Agafonov, A. Immobilization of chitosan onto polypropylene foil via air/solution atmospheric pressure plasma afterglow treatment. Plasma Chem. Plasma Process. 2019, 40, 207-220. [CrossRef] 
34. Chokradjaroen, C.; Rujiravanit, R.; Watthanaphanit, A.; Theeramunkong, S.; Saito, N.; Yamashita, K.; Arakawa, R. Enhanced degradation of chitosan by applying plasma treatment in combination with oxidizing agents for potential use as an anticancer agent. Carbohydr. Polym. 2017, 167, 1-11. [CrossRef]

35. Prasertsung, I.; Damrongsakkul, S.; Saito, N. Degradation of $\beta$-chitosan by solution plasma process (SPP). Polym. Degrad. Stab. 2013, 98, 2089-2093. [CrossRef]

36. Nikitin, D.; Choukourov, A.; Titov, V.; Kuzmicheva, L.; Lipatova, L.; Mezina, E.; Aleksandriiskii, V.; Shelemin, A.; Khalakhan, I.; Slavinska, D.; et al. In situ coupling of chitosan onto polypropylene foils by an Atmospheric Pressure Air Glow Discharge with a liquid cathode. Carbohydr. Polym. 2016, 154, 30-39. [CrossRef] [PubMed]

37. Vasilieva, T.; Sigarev, A.; Kosyakov, D.; Ul'yanovskii, N.; Anikeenko, E.; Chuhchin, D.; Ladesov, A.; Hein, A.M.; Miasnikov, V. Formation of low molecular weight oligomers from chitin and chitosan stimulated by plasma-assisted processes. Carbohydr. Polym. 2017, 163, 54-61. [CrossRef] [PubMed]

38. Vasiliev, M.; Vasilieva, T.; Hein, A.M. Hybrid plasma chemical reactors for bio-polymers processing. J. Phys. D Appl. Phys. 2019, 52, 335202. [CrossRef]

39. Vasiliev, M.; Vasilieva, T. Encyclopedia of Plasma Technology; Shohet, J.L., Ed.; CRC Press, Taylor and Francis Inc.: Boka Ralton, FL, USA, 2016; pp. 152-166.

40. Aleksandrov, N.L.; Vasil'ev, M.N.; Lysenko, S.L.; Makhir, A.K. Experimental and theoretical study of a quasi-steady electron-beam plasma in hot argon. Plasma Phys. Rep. 2005, 31, 425-435. [CrossRef]

41. Vasilieva, T.M.; Vasiliev, M.N.; Garaeva, V.V.; Zlobin, I.S.; Mint, Z.Y.; Htau, K.M.; Kyaw, H.W.Y.; Zaw, H.K.K. Hybrid plasmaProspects for applications in medicine and biology. Russ. Phys. J. 2020, 62, 2092-2100. [CrossRef]

42. Vasilieva, T.; Chuhchin, D.; Lopatin, S.; Varlamov, V.; Sigarev, A.; Vasiliev, M. Chitin and cellulose processing in low-temperature electron beam plasma. Molecules 2017, 22, 1908. [CrossRef]

43. Quackenbos, H.M. Relation between intrinsic viscosity and molecular weight. J. Appl. Polym. Sci. 1980, 25, 1435-1442. [CrossRef]

44. Hirai, A.; Odani, H.; Nakajima, A. Determination of degree of deacetylation of chitosan by $1 \mathrm{H}$ NMR spectroscopy. Polym. Bull. 1991, 26, 87-94. [CrossRef]

45. Lavertu, M.; Xia, Z.; Serreqi, A.N.; Berrada, M.; Rodrigues, A.; Wang, D.; Buschmann, M.D.; Gupta, A. A validated 1H NMR method for the determination of the degree of deacetylation of chitosan. J. Pharmaceut. Biomed. Anal. 2003, 32, 1149-1158. [CrossRef]

46. Burrell, T.; Fozard, S.; Holroyd, G.H.; French, A.P.; Pound, M.P.; Bigley, C.J.; Forde, B.G. The Microphenotron: A robotic miniaturized plant phenotyping platform with diverse applications in chemical biology. Plant Methods 2017, 13, 10. [CrossRef] [PubMed]

47. Underwood, A.J. Experiments in Ecology: Their Logical Design and Interpretation Using Analysis of Variance; Cambridge University Press: Cambridge, UK, 1997.

48. Goñi, O.; Quille, P.; O'Connell, S. Ascophyllum nodosum extract biostimulants and their role in enhancing tolerance to drought stress in tomato plants. Plant Physiol. Biochem. 2018, 126, 63-73. [CrossRef] [PubMed]

49. Carmody, N.; Goñi, O.; Łangowski, Ł.; O'Connell, S. Ascophyllum nodosum extract biostimulant processing and its impact on enhancing heat stress tolerance during tomato fruit set. Front. Plant Sci. 2020, 11, 807. [CrossRef] [PubMed]

50. Ertani, A.; Francioso, O.; Tinti, A.; Schiavon, M.; Pizzeghello, D.; Nardi, S. Evaluation of seaweed extracts from Laminaria and Ascophyllum nodosum spp. as biostimulants in Zea mays L. using a combination of chemical, biochemical and morphological approaches. Front. Plant Sci. 2018, 9, 428. [CrossRef]

51. Yin, H.; Du, Y.; Dong, Z. Chitin oligosaccharide and chitosan oligosaccharide: Two similar but different plant elicitors. Front. Plant Sci. 2016, 7, 22. [CrossRef]

52. Qandil, A.M.; Marjic, T.J.; Al-Taanid, B.M.; Khalede, A.H.; Badwan, A.A. Depolymerization of HMW into a predicted LMW chitosan and determination of the degree of deacetylation to guarantee its quality for research use. J. Excip. Food Chem. 2018, 9 , 51-63.

53. Kim, S.K.; Je, J.Y. Continuous Production of Chitooligosaccharides by Enzymatic Hydrolysis in Chitin, Chitosan and Their Derivatives: Biological Activities and Applications; Kim, S., Ed.; CRC Press, Taylor and Francis Group: Boca Raton, FL, USA, $2010 ;$ p. 47.

54. Lopez-Moya, F.; Escudero, N.; Zavala-Gonzalez, E.A.; Esteve-Bruna, D.; Blázquez, M.A.; Alabadí, D.; Lopez-Llorca, L.V. Induction of auxin biosynthesis and WOX5 repression mediate changes in root development in Arabidopsis exposed to chitosan. Sci. Rep. 2017, 7, 16813. [CrossRef]

55. Asghari-Zakaria, R.; Maleki-Zanjani, B.; Sedghi, E. Effect of in vitro chitosan application on growth and minituber yield of Solanum tuberosum L. Plant Soil Environ. 2009, 55, 252-256. [CrossRef]

56. Dzung, P.D.; Phu, D.V.; Du, B.D.; Ngoc, L.S.; Duy, N.N.; Hiet, H.D.; Nghia, D.H.; Thang, N.T.; Le, B.V.; Hien, N.Q. Effect of foliar application of oligochitosan with different molecular weight on growth promotion and fruit yield enhancement of chili plant. Plant Prod. Sci. 2017, 20, 389-395. [CrossRef]

57. Sultana, S.; Islam, M.; Khatun, M.A.; Hassain, M.A.; Huque, R. Effect of foliar application of oligo-chitosan on growth, yield and quality of tomato and eggplant. Asian J. Agric. Res. 2017, 11, 36-42. [CrossRef]

58. Uddin, I.; Islam, J.M.M.; Haque, A.; Zubair, A.; Barua, R.; Rahaman, S.; Rahman, L.; Khan, M.A. Significant influence of gamma-radiation-treated chitosan and alginate on increased productivity as well as improved taste and flavor of pineapple. Int. J. Fruit Sci. 2020, 20, 455-469. [CrossRef] 
59. Moller, M.N.; Li, Q.; Vitturi, D.A.; Robinson, J.M.; Lancaster, J.R.; Denicola, A. Membrane "lens" effect: Focusing the formation of reactive nitrogen oxides from the ${ }^{*} \mathrm{NO} / \mathrm{O} 2$ reaction. Chem. Res. Toxicol. 2007, 20, 709-714. [CrossRef]

60. Buxton, G.V.; Greenstock, C.L.; Helman, W.P.; Ross, A. Critical review of rate constants for reactions of hydrated electrons, hydrogen atoms and hydroxyl radicals (OH/O-) in aqueous solution. J. Phys. Chem. Ref. Data 1988, 17, 513. [CrossRef]

61. Duan, J.; Kasper, D.L. Oxidative depolymerization of polysaccharides by reactive oxygen/nitrogen species. Glycobiology 2011, 21, 401-409. [CrossRef] [PubMed]

62. Boric, M.; Puliyalil, H.; Novak, U.; Likozar, B. An intensified atmospheric plasma-based process for the isolation of the chitin biopolymer from waste crustacean biomass. Green Chem. 2018, 20, 1199-1204. [CrossRef]

63. Xin, R.; Xie, W.; Xu, Z.; Che, H.; Zheng, Z.; Yang, X. Efficient extraction of chitin from shrimp waste by mutagenized strain fermentation using atmospheric and room-temperature plasma. Int. J. Biol. Macromol. 2019. [CrossRef]

64. Tantiplapol, T.; Singsawat, Y.; Narongsil, N.; Damrongsakkul, S.; Saito, N.; Prasertsung, I. Influences of solution plasma conditions on degradation rate and properties of chitosan. Innov. Food Sci. Emerg. Technol. 2015, 32, 116-120. [CrossRef]

65. Titov, V.A.; Lipatova, I.M.; Mezina, E.A.; Kuz'micheva, L.A. Plasma-chemical destruction and modification of chitosan in solution. High Energy Chem. 2016, 50, 411-415. [CrossRef]

66. Na, L.; Yingchun, F.; Jie, L.; Yan, S.; Kefeng, S.; Yan, W. Electrical characteristics of pulsed corona discharge plasmas in chitosan solution. Plasma Sci. Technol. 2014, 16, 128-133. [CrossRef]

67. Trombotto, S.; Ladavière, C.; Delolme, F.; Domard, A. Chemical preparation and structural characterization of a homogeneous series of chitin/chitosan oligomers. Biomacromolecules 2008, 9, 1731-1738. [CrossRef]

68. Grifoll-Romero, L.; Pascual, S.; Aragunde, H.; Biarnés, X.; Planas, A. Chitin deacetylases: Structures, specificities, and biotech applications. Polymers 2018, 10, 352. [CrossRef] [PubMed]

69. Zaeni, A.; Safitri, E.; Fuadah, B.; Sudiana, I.N. Microwave-assisted hydrolysis of chitosan from shrimp shell waste for glucosammine hydrochlorid production. J. Phys. Conf. Ser. 2017, 846, 012011. [CrossRef]

70. Piątkowski, M.; Janus, Ł.; Radwan-Pragłowska, J.; Raclavsky, K. Microwave-enhanced synthesis of biodegradable multifunctional chitosan hydrogels for wastewater treatment. eXPRESS Polym. Lett. 2017, 11, 809-819. [CrossRef]

71. National Research Council. Microwave Processing of Materials; The National Academies Press: Washington, DC, USA, 1994. [CrossRef]

72. Kalganova, S.G.; Arkhangelsky, Y.S.; Lavrentiev, V.A.; Trigorly, S.V. Scientific basis for modification of polymer materials in a microwave electromagnetic field. J. Electrotech. 2017, 14, $26-35$.

73. Undri, A.; Rosi, L.; Frediani, M.; Frediani, P. Microwave pyrolysis of polymeric materials. In Microwave Heating; Chandra, U., Ed.; IntechOpen: Rijeka, Croatia, 2011; pp. 207-232.

74. Vasiliev, M.N.; Mahir, A.H. Electron-beam plasma systems in industrial and aerospace applications. In Proceedings of the 24th Summer School and International Symposium on the Physics of Ionized Gases, Novi Sad, Serbia, 25-29 August 2008; pp. 421-426.

75. Vasilieva, T.M.; Bayandina, D.V. An experimental complex for studying the operation of Beam-Plasma Reactors for biomedical applications. Instrum. Exp. Tech. 2010, 53, 289-296. [CrossRef] 